\title{
Feminismos e antirracismo: entraves e intersecções. Entrevista com Luiza Bairros, ministra da Secretaria de Políticas de Promoção da Igualdade Racial (Seppir)
}

\author{
Sonia E. Alvarez \\ Universidade de Massachusetts, Amherst
}

\begin{abstract}
A ministra Luiza Bairros, que assumiu o seu atual cargo no governo de Dilma Rouseff em janeiro de 2011 como ministra de Estado chefe da Secretaria de Políticas de Promoção da Igualdade Racial da Presidência da República, é uma notória intelectual nas áreas de estudos feministas, relações raciais e sociologia, com longa história de militância tanto nos movimentos negros quanto nos feministas. Sua inabalável dedicação às lutas pelos direitos das mulheres e dos afrodescendentes, em especial das mulheres negras, se reflete também na sua atuação destacada em diversos órgãos governamentais, como titular da Secretaria de Promoção da Igualdade do Estado da Bahia (Sepromi), e em instituições internacionais, como consultora do Sistema Nações Unidas no Brasil no processo da III Conferência Mundial contra o Racismo, e em outros projetos de interesse da população afro-brasileira.

Esse entrecruzamento singular de caminhos intelectuais e políticos coloca a ministra em uma posição sui generis para analisar com contundência as questões complexas abordadas na entrevista que me concedeu em 14 de dezembro de 2011, em Brasília. Procurei indagar como a ministra, a partir da sua gestão no governo e à luz de sua longa trajetória política nos movimentos negros e feministas, avaliava os pontos de
\end{abstract}

Copyright $\odot 2012$ by Revista Estudos Feministas 
(des)encontro entre a luta antirracista e os feminismos e movimentos de mulheres no Brasil, procurando delinear os caminhos pelos quais questões relacionadas à raça e ao racismo têm circulado nos diversos espaços feministas, e vice-versa.

834 Estudos Feministas, Florianópolis, 20(3): 833-850, setembro-dezembro/2012 
Sonia E. Alvarez: O meu interesse é saber como você entende a relação dos feminismos vários com os diversos movimentos negros, e as articulações de ambos os movimentos com a gestão pública: o feminismo e o movimento negro no Estado. Mas vamos primeiro pontuar algumas questões. Queria pedir a você que falasse sobre a sua trajetória política e profissional. Desde 2008 você está trabalhando no Estado, primeiro na Bahia e agora em Brasília em...

Luiza Bairros: Janeiro de 2011.

SEA: Podíamos então começar com a sua trajetória política e o que a levou a esse lugar. Eu sei que você tem uma longa trajetória política em ambos os movimentos.

LB: É difícil saber o que exatamente lhe traz para o lugar que você ocupa no momento. Até porque não havia uma intencionalidade nesse sentido. Toda a minha trajetória de militância se deu em primeiro lugar no movimento negro. E, pelas contradições que aí a gente identificava nas relações entre homens e mulheres militantes, passamos, sob a influência de Lélia Gonzalez, a nos reunir num grupo de mulheres negras.

SEA: Dentro do próprio movimento negro?

LB: No caso, dentro do MNU, isso no início dos anos 1980. Com essa articulação das mulheres no Movimento Negro Unificado é que começa a minha relação com o movimento de mulheres e com o movimento feminista, mais especificamente. Ao longo dos anos 1980 e 1990 a questão das mulheres negras foi ficando cada vez mais evidente, como uma forma de pensar e uma forma de atuação diferenciada no movimento negro. Eu deixei de participar do MNU na metade dos anos 1990, mas dei seguimento à militância. Não mais vinculada a uma organização específica, mas cada vez mais próxima da atuação enquanto mulher. Quer dizer, naquilo que ser mulher negra possibilita uma organização política para intervenção na sociedade. Paralelamente a isso, essa questão sempre foi muito presente, do ponto de vista da minha reflexão acadêmica, inclusive.

SEA: Você entrou no MNU bem no começo do movimento? LB: Em 1979.

SEA: E daí de dentro do MNU forma-se essa articulação? LB: Essa articulação de mulheres negras. Permaneci no MNU até 1994, depois me desliguei, no momento em que voltei a estudar. Depois virei professora.

SEA: Você fez um estágio nos Estados Unidos.

LB: Morei nos Estados Unidos um tempo. 
SEA: Onde foi nos Estados Unidos?

LB: Em Michigan, estudei na Michigan State University. Na volta, fui ensinar na Universidade Católica de Salvador, ao mesmo tempo eu era pesquisadora associada do Centro de Recursos Humanos, um centro de pesquisas sociais da UFBA. Lá, coordenei um projeto de intercâmbio entre pesquisadores afro-norteamericanos e estudantes afro-brasileiros. Paralelamente, trabalhei com o PNUD, que foi um espaço na verdade criado por pressão do movimento negro, o que me permitiu conhecer outras agências internacionais, como o DFID, o Departamento para o Desenvolvimento Internacional do Reino Unido. Aí começamos a desenvolver o Programa de Combate ao Racismo Institucional. Então, o objetivo do Programa era trabalhar como o racismo opera especialmente no setor público. Foi nesse programa que eu comecei a refinar o meu pensamento e a minha prática sobre a ausência de políticas para a população negra, ou ausência de políticas de igualdade racial, e o que impede que isso aconteça dentro das organizações. Trabalhamos a partir de um conceito de racismo institucional e, com o apoio internacional, desenvolvemos uma experiência na Prefeitura de Recife, no Ministério Público de Pernambuco e, depois, na Prefeitura Municipal de Salvador.

SEA: Qual era a natureza desses programas? Tentar identificar os pontos de resistência no aparelho do Estado?

LB: Existem várias possibilidades de você trabalhar com essa questão. No nosso caso, optamos por fazer um trabalho de capacitação de servidores e gestores públicos. E acabamos, no processo, em parceria com o Instituto Amma Psique e Negritude, dirigido pela Maria Lucia Silva, em São Paulo, criando uma metodologia de capacitação com a abordagem da psicologia social. Quer dizer, como fazer com que servidores e gestores identifiquem os entraves que o racismo causa na atuação de uma instituição e qual o efeito disso nos serviços que são prestados. São serviços que acabam deixando de atingir determinado setor da população ou, se atingem, o fazem de maneira muito precária. Isso é muito evidente, por exemplo, na saúde: quais as dificuldades no atendimento, quais obstáculos o racismo interpõe na relação de um negro usuário do serviço com quem trabalha na unidade de saúde? Existem até regras criadas pela instituição, mas os servidores, não importa em que nível estejam, por conta de suas próprias crenças e percepções, impedem que elas sejam cumpridas. É o que ainda acontece no uso do quesito cor, que na área da saúde tem uma importância muito grande, porque através disso é que a gente conseguiria produzir estatísticas bem mais acuradas, a partir de registros administrativos sobre a situação de saúde da população que procura os serviços públicos. Então, identificar a cor da pessoa que está sendo atendida é algo que existe como

836 Estudos Feministas, Florianópolis, 20(3): 833-850, setembro-dezembro/2012 
possibilidade nos sistemas de informações do Ministério da Saúde. No entanto, por decisão de um funcionário, esse quesito simplesmente pode não ser coletado, porque o servidor acha que se perguntar vai constranger ou porque acha que isso não tem importância nenhuma, que raça não existe. Portanto, o Programa trabalhava com essas dimensões; todas as interposições que vão acontecendo no dia a dia do trabalho. Por exemplo, em situações de sala de aula, professores frequentemente rotulam alunos e alunas negras, "esse menino é desatencioso" ou "essa menina não aprende nada, nunca". São várias situações, várias possibilidades de interferência do racismo nas práticas cotidianas de uma instituição, especialmente no setor público, que acabam provocando desvantagens para a população negra. Foi assim que eu comecei a mexer com política pública. Fiquei algum tempo trabalhando com esse programa, que foi uma experiência bastante rica. Eu estava nessa condição, prestando consultoria, quando na Bahia o Partido dos Trabalhadores ganhou a eleição de 2006 ao governo do estado, pela primeira vez desbancando uma oligarquia política que estava no poder já há muitos anos. No novo governo foi criada, em 2007, a Secretaria de Promoção da lgualdade, que tinha uma característica diferenciada porque reunia igualdade racial e política para as mulheres. Num primeiro momento, foi escolhido um homem para dirigir essa secretaria, o deputado Luiz Alberto, que também vinha de uma trajetória de movimento negro. Ele ficou durante um ano e meio como secretário e depois resolveu retornar para a atividade parlamentar, que é a grande vocação dele. Com a volta de Luiz Alberto à Câmara Federal, meu nome foi considerado para substituí-lo. Isso foi em agosto de 2008, quando fui para a Secretaria de Promoção da lgualdade para trabalhar exatamente com as duas questões às quais eu tinha me dedicado como militante. E a partir daí foram sendo criadas, eu acredito, as possibilidades para eu agora me tornar ministra. Mas acho que isso é muito mais devido ao fato da eleição da presidenta, Dilma Rousseff, e da decisão que ela tomou de ter como meta pelo menos $30 \%$ de mulheres no ministério.

SEA: Que ela não atingiu completamente.

LB: Chegou muito perto. São $29 \%$ de mulheres.

SEA: O que eu entendi é que alguns partidos aliados não apresentaram nomes. Não foi por escolha ou negligência dela. LB: Não. Acho que pela vontade dela seriam pelo menos 12 mulheres, desde o início, no ministério. O ministério começou com nove mulheres, hoje somos dez. Então, a eleição da presidenta, Dilma, foi fundamental para que alguém com a trajetória como a minha pudesse ocupar esse cargo. Acho que em outras circunstâncias isso não teria acontecido, de jeito nenhum. 
SEA: É uma reflexão interessante. Voltando à trajetória, tem muito sentido isso de você começar a se preocupar com o racismo institucional como conceito e como trabalhar dentro do Estado, e o fato de que o processo de Durban traz a institucionalidade mais centralmente como preocupação para o movimento negro, né?

LB: Exatamente.

SEA: Durban foi uma espécie de "efeito Beijing" para o movimento negro.

LB: De certa forma, sim. A partir de Durban, o que acontece? Você tem um documento que não só coloca, pela primeira vez, os afrodescendentes como alvos do racismo, mas também define que o Estado tem como responsabilidade primária combater o racismo. Isso foi muito bem aproveitado no caso brasileiro. O movimento negro utilizou o processo de Durban para, cada vez mais, forçar o Estado a assumir essa responsabilidade. Durban é um ponto de inflexão no enfrentamento ao racismo no Brasil. Tanto é que dois anos depois da Conferência, com a eleição do Partido dos Trabalhadores no governo federal, ocorre a criação da Seppir.

SEA: Vamos pegar então o processo de Durban para pensar movimentos e relação entre os movimentos e em relação ao Estado. Por exemplo, pelo que eu acompanhei do processo de Durban, as mulheres negras tiveram um papel bastante destacado.

LB: Muito importante.

SEA: E também Durban teve repercussões interessantes dentro do movimento feminista, além do movimento negro. Como você entende o que esse processo trouxe para a discussão do movimento negro? O protagonismo das mulheres negras se deu de que forma dentro desse processo?

LB: Como eu entendo, as mulheres negras acumularam condições políticas para participar de forma mais ativa do processo de Durban, também pela proximidade com o movimento feminista. Já tinham uma experiência com conferências mundiais; as mulheres negras se apropriaram mais rapidamente das ferramentas que você precisa para participar de uma conferência das Nações Unidas, que têm um processo bastante longo, feito de várias instâncias e etapas que se realizam em diferentes lugares do mundo. Esses processos, na prática, são levados pelas representações de governos e acompanhados por setores da sociedade civil que se credenciem junto às Nações Unidas para influenciar as posições que o país toma dentro dessas instâncias. As Nações Unidas têm uma etiqueta, uma linguagem, procedimentos definidos sobre como você acessa ou não determinados espaços. O conhecimento disso estava 
nas mãos das mulheres negras, que aprenderam com a participação com o movimento feminista nas conferências de mulheres. Outros setores do movimento negro quase não tinham experiência nessa área.

SEA: E ao fazer isso consegue se colocar mais proeminentemente, mais visivelmente a questão de gênero no processo de Durban, também, no Brasil?

LB: Não necessariamente. As mulheres negras produziram bons documentos e debates colocando seu ponto de vista sobre o racismo, mas isso não gerou uma predominância sobre as outras visões. Como eu percebo, você estava ali engajada num processo amplo, no esforço políico de conseguir espaços para assegurar que a questão do racismo constasse do documento final, da declaração final, da forma mais próxima possível das perspectivas das populações negras no mundo e, mais especificamente, na América Latina e no Brasil. Eu não tenho memória da questão da mulher negra sendo discutida de modo mais amplo nas reuniões entre os países. Isso se deu mais no processo preparatório em espaços da sociedade civil.

SEA: Quando você diz isso, significa que não tem havido muita influência dessa temática dentro do movimento negro?

LB: A questão não é essa. Como você trabalha com a ideologia racista do ponto de vista dos seus efeitos na vida das pessoas? Durban foi uma conferência mundial e os negros não eram o foco exclusivo, entendeu? Tratava de africanos e afrodescendentes, asiáticos e descendentes de asiáticos, indígenas, migrantes, vários grupos que sofrem racismo e discriminação racial, xenofobia e intolerâncias correlatas. Então, o que você assegura nos documentos são as declarações de caráter mais geral, porque especificar todas as possibilidades de discriminação dentro de cada grupo é, sem dúvida alguma, muito difícil. Mas você tem nos documentos dessa III Conferência referências às mulheres, como sofrem de forma diferenciada os efeitos do racismo, e recomendações de medidas especiais para esse segmento. Mas o documento não se detém a isso. A própria utilização da palavra "afrodescendente" no contexto de Durban é um exemplo da necessidade de generalizações, pois é como você se refere aos negros de todas as partes do mundo com uma denominação só que seja entendida no Brasil, nos Estados Unidos, no Canadá, na Colômbia, no Equador e por aí vai. Embora o termo historicamente utilizado no Brasil para nos definirmos seja "negro". Então, o documento final, que continua superatual, traz declarações e propostas de medidas para tratar situações vividas por determinados povos no mundo, submetidos ao racismo e à discriminação racial, à xenofobia e a intolerâncias correlatas. 
SEA: Mas, fora o processo oficial em si, você acha que tanto a presença das mulheres, do protagonismo das mulheres negras no processo, quanto algumas referências e debates internos podem ter contribuído para trazer as questões de interesse específico das mulheres negras?

LB: A consequência disso é que você teve a afirmação do movimento de mulheres negras dentro do movimento negro; é quando, efetivamente, ele se descola do movimento negro tal como a gente o conhecia até então. Ganha uma identidade própria.

SEA: Dentro do movimento negro.

LB: Exatamente.

SEA: Porque ele já tinha identidade própria dentro do movimento feminista. Mas dentro do movimento negro...

LB: Eu acho que se especifica completamente porque no processo de Durban, inclusive, é que foi criada a AMNB, a Articulação de Organizações de Mulheres Negras Brasileiras. Como ator político, isso deu uma nitidez que foi muito importante.

SEA: Que tem impacto tanto no movimento negro como no movimento feminista.

LB: Não tenho dúvida.

SEA: Durban é um dos momentos de virada na discussão da questão racial dentro do movimento feminista; outro foi o processo Beijing, onde também as mulheres negras tiveram um protagonismo importante. Como você vê a relação entre ambos os processos?

LB: Beijing, eu só acompanhei por notícias, foi no período em que eu estava fora do Brasil. Mas acho que não se compara com Durban, porque aí as questões de gênero não são o ponto de partida para a discussão sobre as mulheres negras. O ponto de partida é a questão racial mesmo. Em minha opinião, se você especifica o racismo, tem uma possibilidade maior de dar conta das questões das mulheres negras mais do que quando você especifica o sexismo. Nesse sentido, para nós, Durban é muito mais definitivo do que Beijing, não tenho dúvida.

SEA: E, posterior a Durban, mulheres negras continuam tendo uma atuação de destaque em ambos os movimentos. Quais as conquistas e as resistências em relação à agenda das mulheres negras em ambos esses espaços?

LB: Você se coloca para o movimento feminista a partir da identidade de mulher negra, mas para dentro do movimento de mulheres negras também passam a ocorrer outros movimentos. Você começa a assistir a um processo que a gente ainda não discutiu tanto quanto deveria no qual vão se especificando outras

840 Estudos Feministas, Florianópolis, 20(3): 833-850, setembro-dezembro/2012 
identidades entre as mulheres negras, e isso aconteceu muito rapidamente. Se você pensa no que foi o caminho anterior até a gente se constituir como mulher negra e no que é o momento atual, você percebe um outro movimento que é para especificar quem são essas mulheres. É como se em determinado momento mulher negra tivesse deixado de ser uma categoria universal, porque não representa mais todas as possibilidades dessa experiência numa sociedade como a brasileira.

SEA: Que tipo de possibilidades?

LB: Tem mulheres quilombolas, de terreiro, jovens, lésbicas. Só estou me lembrando aqui das mais visíveis...

SEA: Quer dizer, surgem multiplicidades, múltiplas identidades de mulheres negras.

LB: Surge o que eu chamo de múltiplas possibilidades de organização política da identidade negra. É isso.

SEA: Cada uma dessas vertentes de organização política se articula de diferentes formas?

LB: Vão começando a formar articulações de modos diferenciados. As trabalhadoras domésticas formam outro segmento também importante que vai se articulando de modos específicos.

SEA: Como há muito tempo você não pode mais falar de um movimento de mulheres ou um feminismo, não pode mais falar de um movimento de mulheres negras?

LB: Exatamente. O mesmo processo. Digamos, são círculos que vão se formando em torno de um mesmo núcleo para pensar a identidade de mulher negra. Isso é algo muito forte que tem caracterizado o movimento de mulheres negras hoje.

SEA: E você acha que isso tem enriquecido a possibilidade de influência desse movimento em relação a outros movimentos? LB: Lógico, com isso você ganha muito mais penetração em diversos setores e espaços de discussão. É muito interessante o caso das trabalhadoras domésticas, só para dar um exemplo recente. No processo de buscar na OIT a aprovação de uma convenção específica para o trabalho doméstico, o trabalho político foi desenvolvido por mulheres negras, trabalhadoras domésticas. Elas estiveram na linha de frente, embora outras mulheres negras também participassem do debate. A convenção foi finalmente aprovada na Conferência Internacional da OIT que aconteceu em junho desse ano [2011], pelo esforço das próprias trabalhadoras domésticas. Nas questões relativas às quilombolas, também elas estão à frente de tudo. Isso é muito rico. Hoje, aqui em Brasília, a partir da democratização do governo federal, passou a ser um lugar para onde converge a 
pressão dos movimentos sobre o Estado, você encontra pessoas negras, mulheres negras das mais diferentes organizações, fazendo o trabalho político nos seus próprios termos. O que nos une a todos e todas é a luta contra o racismo, mas essa luta acontece a partir de diferentes lugares.

SEA: Isso é importante, sim. Acho que nem sempre se reconhece do ponto de vista de fora dos movimentos negros. Não sei se tem necessariamente esse reconhecimento no próprio movimento de mulheres. Porque essas diferentes instâncias dialogam com diferentes instâncias dos movimentos de mulheres e feministas. Eu queria saber do ponto de vista de onde você está parada agora, quais você vê como os principais ganhos da questão racial dentro do feminismo e quais as principais resistências? Quais os avanços em relação a, digamos, 10, 15, 20 anos atrás? LB: Você tem hoje um feminismo que se define como antirracista no Brasil, algo que não existia antes. Agora, como eu vou localizar isso na prática, Sonia? Eu acho que a experiência da $A M B$, Articulação de Mulheres Brasileiras, é muito interessante nesse sentido. A AMB tem uma forma de organização bastante flexível; ela atua com fóruns de mulheres em diversos estados do Brasil, e sempre me impressiona a quantidade de mulheres negras que fazem parte disso. Então, eu considero um avanço ter uma articulação de mulheres que é geral, vamos dizer assim, mas com a presença de mulheres negras. Isso era quase impossível há anos, porque o grau de tensão e de enfrentamento entre mulheres negras e mulheres brancas era pesado demais. Hoje há certo esfriamento dessa tensão que, fazendo uma análise, digamos, otimista, é dado por pelo menos dois fatores. Por um lado, o fato de que as feministas finalmente concordam que as mulheres não são todas brancas e que, portanto, o espaço político vai ter que ser compartilhado entre muitas mulheres diferentes entre si. E, por outro lado, acho que há uma segurança maior das mulheres negras de que o fato de você trabalhar numa organização que não se define como negra não elimina as suas possibilidades de expressão a partir do seu lugar racial.

SEA: Muito mais do que 10 anos atrás.

LB: Sim, sim. Eu sempre acompanhei o trabalho da AMB, participei de reuniões e tudo mais, pela flexibilidade que ela tem. Você pode não estar ligada a uma organização, mas se está ligada a um fórum, você participa do debate igual. Logo que eu cheguei ao ministério, num encontro nacional da Articulação, tive uma reunião específica com as mulheres negras porque elas pediram que a gente sentasse para conversar, sem nenhum receio de que isso pudesse ser questionado pelas mulheres brancas. Essa segurança está dada e é um ganho importante. As resistências ainda existem, mas são mais difíceis de ser manifestadas, apesar de as organizações feministas no Brasil 
continuarem sendo de maioria branca. Quer dizer, tem uma barreira final aí que não foi totalmente vencida ainda. Na atuação das redes, você percebe, como eu falei, a presença de brancas e negras, mas o mesmo não ocorre nas organizações especificamente.

SEA: Nos Estados Unidos se chamaria o feminismo organizado, as organizações especificamente de advocacy, as ONGs feministas.

LB: Essa barreira não foi quebrada ainda, porque não tem, ou se existe eu não tenho conhecimento, uma organização feminista que seja paritariamente formada por mulheres brancas e negras. Essa é uma dimensão do que ainda é preciso romper em termos de resistências. As organizações ou são brancas ou são negras.

SEA: Alguns pontos de uma agenda antirracista têm sido incorporados por alguns setores do movimento feminista. Eu concordo plenamente que hoje em dia pelo menos existem setores, especialmente das mulheres jovens, que são muito mais receptivas à questão racial, nem imaginam o feminismo sem um componente antirracista. Acho que há um nível de reconhecimento bastante significativo da importância da questão racial. Agora, até que ponto a agenda antirracista que se assume enquanto tal no feminismo se aproxima da agenda antirracista do movimento negro?

LB: Essas questões são tão complexas, absolutamente complexas! Essas coisas só acontecem se você respeita as possibilidades, se respeita o que cada uma tem de específico na sua própria experiência como mulher. A gente parou de brigar. As feministas pararam, por exemplo, de dizer que a gente não é feminista. Pode ser que continuem achando, mas pararam de dizer. Isso já ajudou a distensionar um monte, já se admite que existe um feminismo negro. Agora, esses feminismos mantêm distâncias e diferenças muito marcadas. As mulheres negras, qualquer uma, por mais feminista que seja, muito dificilmente vão ter uma leitura de sociedade a partir e para as mulheres negras. Nos outros feminismos isso é possível, mas aqui é um ponto de vista da mulher negra em relação à sociedade e à população negra.

SEA: E que só nesse feminismo negro que você vai ter...

LB: Isso só é possível aqui. Então, a agenda antirracista, de uma e de outra, tem diferenças muito marcadas.

SEA: Nesse sentido, é por isso que o único jeito de avançar é trabalhar em coalizão, construir alianças.

LB: Sim, vamos reconhecendo nossas diferenças. Porque se a gente for querer achar que existe uma forma única de ser, não vai dar certo. Por exemplo, a questão da mortalidade da juventude 
negra no Brasil, hoje, é uma pauta perfeitamente aceitável nas organizações de mulheres negras, mas muito dificilmente vai ser levada pelo movimento feminista, entendeu? Ainda que nas organizações de mulheres negras se faça uma especificação para dizer "olha, não são apenas os homens negros jovens que morrem, as mulheres negras jovens estão morrendo também". As jovens morrem em menor número, mas as taxas estão crescendo de forma mais acelerada, o que tendencialmente indica que a vitimização por homicídio das mulheres negras é um problema também. Mas você tem que reconhecer que foi a mortalidade dos jovens negros que alterou o perfil demográfico da população masculina no Brasil e isso é um peso enorme para a população negra, para o país. E você não pode, pelo fato de ser mulher, dizer que não lhe diz respeito porque "é homem que está morrendo". Isso não existe! E você não vai impor uma agenda dessas para o movimento de mulheres, não vai.

SEA: Entendi.

LB: Mas aqui, do lado de cá, isso tem importância. Muita importância.

SEA: Agora, em relação a ganhos dos movimentos de mulheres negras ou da questão feminista dentro do movimento negro. Quais os principais ganhos nos últimos 10, 15 anos?

LB: Para além de tudo que eu já falei? De as mulheres negras terem assegurado espaço político no movimento social... mais do que isso?

SEA: Mas em relação a questões específicas. Há algumas resistências ainda dentro do movimento negro?

LB: Não, você não tem mais tanto isso, porque o próprio movimento negro se modificou também. O mesmo processo que houve entre as mulheres negras, de como vão se especificando outras identidades, aconteceu no movimento negro. Porque lá você tem também quilombo, jovem, entre os jovens tem hip-hop e outros grupos. No geral hoje existe um movimento poderoso de juventude negra, movimento contra a intolerância religiosa e por aí vai.

SEA: E dentro de cada um desses setores vão ter diferentes ganhos e diferentes resistências, claro.

LB: Existem as chamadas organizações gerais, que correspondem ao modelo inicial do movimento negro de 1970, 1980, em que cabem homem e mulher e todas as questões são tratadas ali dentro. Hoje, em minha opinião, há uma crise de representatividade no movimento negro, porque as organizações de caráter geral vão perdendo a capacidade de falar pelo conjunto, já que cada um, cada setor fala por si. Elas resistem à perda de representatividade, e aí é que a disputa política se

844 Estudos Feministas, Florianópolis, 20(3): 833-850, setembro-dezembro/2012 
acirra, alimentada pelo esgotamento de determinado modelo. Então, as organizações gerais não incorporam, ou incorporam de uma forma insuficiente, as questões novas que vão aparecendo, com essas novas formações em que a preocupação com a mulher negra e outros segmentos é muito maior, é a razão de ser mesmo da sua existência. Um exemplo simples desse processo aconteceu no Afro 21, encontro do encerramento do Ano Internacional dos Povos Afrodescendentes, que foi realizado agora em Salvador. Para assistir à reunião de chefes de Estado, foi definido, pelo cerimonial da Presidência, um número $\mathrm{x}$ de representantes de sociedade civil. Quando as organizações se sentaram para escolher quem iria, a necessidade de as mulheres estarem representadas estava colocada. Todo mundo já sabe que não pode aparecer só com homem, porque, afinal de contas, o movimento é formado principalmente pelas mulheres. Quando se trata de representação, essa preocupação aparece. Isso não significa que no dia a dia as relações entre mulheres e homens negros tenham melhorado a ponto de as mulheres desfrutarem, automaticamente, de uma posição de igualdade com os homens. Não, as disputas permanecem. Modificadas, mas permanecem. Já faz alguns anos, eu escrevi uma coisa pequenininha: temos uma população negra imensa no país, totalmente fora ou com uma participação muito rala na vida política do país. Então, para você como negro, a atuação política mais garantida é a que existe no que chamamos genericamente de movimento negro. E esse espaço é exíguo demais; em termos de expressão política é muito pequeno. À medida que as mulheres negras ganham a sua própria identidade como movimento, aumenta mais a sensação de ameaça do ponto de vista dos homens. Até por isso essas relações ainda não conseguiram encontrar o seu leito tranquilo.

SEA: Acho importante a ideia de que há um espaço exíguo e todo mundo está disputando, é uma concepção instigante.

LB: Você quase não tem outros lugares para se expressar politicamente. As pessoas negras vão para o partido político, estão lá em grandes números, mas você não tem lideranças de expressão negras nacionalmente reconhecidas. Não tem. Muitas pessoas vão para o partido político e acabam voltando para cá, porque aqui vão ser ouvidas, vão ser consideradas.

SEA: É, imagino que esse espaço político possa ficar apertado e disputado mesmo. Nesse sentido, para ir encerrando, eu queria pedir que você voltasse ao lugar que você ocupa, justamente, porque você não está mais exclusivamente no espaço do movimento.

LB: Não estou, mas também não saí. Você não sai disso! Especialmente nesse lugar em que eu estou. Se eu estivesse em outro cargo, até poderia, mas, na verdade, querendo ou não, a 
Seppir é decorrência do movimento negro. E ela é, no âmbito institucional, um outro espaço também reduzido como o movimento negro. Talvez, menor ainda. Acho que o mesmo poderia ser dito em relação à Secretaria de Políticas para as Mulheres (SPM), que também surgiu de um processo provocado pelo movimento de mulheres. Em termos institucionais, é sempre muito difícil corresponder ao que seria a expectativa de um movimento social.

SEA: Isso nos remete ao conceito de racismo institucional com o qual você começou, de como negociar, navegar, dentro do racismo institucional, manifestado cotidianamente, no governo federal.

LB: Digamos que a Esplanada dos Ministérios seja representativa do tamanho do governo. Nós somos dois andares, aliás, um e meio. Entendeu? Quando cheguei aqui, usava a seguinte expressão que deu certa confusão, inclusive: a Seppir bateu no teto. Eu fui ter a dimensão mais exata do que é a expressão 'teto de vidro' quando cheguei aqui, porque era assim mesmo que me sentia olhando lá para cima, vendo possibilidades infinitas para o trabalho. As possibilidades que temos aqui são fantásticas, fantásticas! Mas você não fura o teto. Também existe uma demanda, uma expectativa das pessoas negras de virem trabalhar na Seppir. Mas não tem quase ninguém que demande trabalhar no Ministério da Saúde, no Ministério da Educação, no Ministério da Ciência e Tecnologia, no Ministério do Trabalho, entendeu? As pessoas que adquiriram dentro do Estado as competências para trabalhar o racismo ou a promoção da igualdade racial na gestão pública não são absorvidas por essas outras estruturas.

SEA: E terminam sendo absorvidas aqui.

LB: Há uma demanda, mas a estrutura é pequena e não permite que sejam absorvidas.

SEA: Aí a Seppir termina virando uma espécie de reduto também. Há menos articulação aqui na Seppir do que o movimento negro tem fora daqui?

LB: Não, isso não. Aqui as suas possibilidades de articulação são muito grandes. Mas o que acontece, essa é uma discussão que a gente vai ter que enfrentar, é que o modelo tem que ser revisto. Precisa ter o ministério específico? Sim. A gente vai precisar de ministério das mulheres e de igualdade racial ainda por algum tempo. Agora, você tem que criar meios de fazer com que a articulação a partir do ministério específico tenha vida, tenha sustentabilidade dentro dos demais.

SEA: Isso é uma discussão muito longa também dentro do movimento feminista e dentro do movimento negro e dos

846 Estudos Feministas, Florianópolis, 20(3): 833-850, setembro-dezembro/2012 
movimentos em geral. É a questão de, primeiro, como melhor articular as especificidades e, ao mesmo tempo, estabelecer e manter uma presença transversal; e, segundo, qual seria o modelo institucional, organizacional, para melhor realizar ambos os objetivos.

LB: Exatamente. E como você dá sustentabilidade?

SEA: O modelo atual é vocês terem um conselho que tem representações diferentes, certo?

LB: A mesma estrutura da Secretaria das Mulheres. A gente precisa avaliar isso. A AMB criou um espaço que, de tempos em tempos, reúne mulheres da militância, as que estão em conselhos e as que estão na gestão. São três lugares, três perspectivas. E nessas discussões tem aparecido de forma mais nítida a necessidade de rever esse modelo, porque a gente tem problemas com o papel dos conselhos, tem insatisfações com a capacidade dos órgãos de gestão.

SEA: Que tipo de possibilidades haveria? Uma instância mais permanente de representação, uma instância mais consistente de articulação?

LB: Eu não gostaria de me arriscar numa resposta, porque o debate está só começando. É preciso rever a representação governamental nos conselhos, porque muitas vezes ela está desvinculada dos setores que trabalham as agendas de nosso interesse nos ministérios. Os ministérios poderiam ter algum tipo de estrutura, um núcleo, talvez, para trabalhar a promoção da igualdade de forma consistente. Isso teria que ser ligado ao gabinete do ministro ou à secretaria executiva do ministério, de maneira que essas questões tivessem o poder de penetrar na estrutura. No caso da Seppir, que tem uma equipe extremamente reduzida, a inexistência de contrapartes na maioria dos ministérios obriga a gente, o tempo inteiro, a provocar o diálogo com os outros órgãos para não deixar que as coisas morram lá dentro.

SEA: Claro, porque não tem sustentabilidade interna nesses espaços. É relegado às margens. Tem representantes, mas são indivíduos, não são núcleos.

LB: Tem uma série de questões. Os conselheiros governamentais são designados sem que, necessariamente, tenham a possibilidade de assegurar que o que está sendo definido seja efetivamente implementado. A gente trabalhou muito esse ano na relação com os demais ministérios. Agora no início de janeiro, vamos ver o que resultou dos novos acordos e pactuações e qual a estratégia para assegurar que isso realmente seja executado. É um trabalho permanente. Mas no Ministério da Educação tem um lugar em que essas questões são tratadas, existe uma interlocução bem definida. No Ministério da Saúde 
ainda não conseguimos a criação de uma instância específica, embora o tema da saúde da população negra seja trabalhado lá. No Ministério do Trabalho tem muito pouco para além do que a gente provoca e por aí vai.

SEA: E com a SPM vocês têm boas relações em geral?

LB: Muito boas. Voltar a ter uma mulher como ministra da Seppir foi positivo. Há coisas que eu retomo a partir do que foi interrompido com a saída de Matilde Ribeiro. A questão das mulheres negras é uma, porque nos últimos anos havia dúvidas se essa seria pauta da Seppir. É preciso acabar com isso, até porque a SPM é um ministério de articulação, como nós somos, que se interessa em ter ações relativas à mulher em todos os órgãos, inclusive na Seppir. Então, não há contradição. Obviamente, isso melhora muito a relação com a SPM, sem contar com o fato de que trouxemos para a equipe pessoas que vêm do movimento de mulheres negras.

SEA: E que tipo de coisas especificamente?

LB: Esse ano ainda fizemos muito pouco. Por conta da limitação estrutural, tivemos que priorizar a mortalidade da juventude negra, um plano que envolve nove ministérios. $O$ tema das mulheres ficou mais restrito ao trabalho doméstico. A preparação para a Conferência da OIT implicou um processo de articulação com os Ministérios do Trabalho e das Relações Exteriores para assegurar uma posição brasileira consistente com as expectativas dos sindicatos das trabalhadoras domésticas. O governo brasileiro teve um papel muito bom no sentido de costurar com outros países a aprovação da convenção específica. Terminada a Conferência, a Seppir passou a acompanhar no legislativo os projetos de lei relacionados ao trabalho doméstico. Tudo isso foi feito junto com a SPM; fizemos uma nota conjunta para subsidiar a presidenta da República nos vetos a uma lei, impedindo oportunismos dos planos de saúde em relação a esse contingente. São sete milhões de trabalhadores domésticos no Brasil.

SEA: E para 2012 quais as prioridades?

LB: Nós temos, no Conselho Nacional de Promoção da Igualdade Racial, representações das redes de mulheres negras e também uma comissão para trabalhar esse tema. Para 2012, a gente pretende que essa comissão nos dê sugestões para poder atuar para além do trabalho doméstico. O nosso grande desafio é começar a tirar do papel o Eixo Nove do segundo Plano Nacional de Políticas para as Mulheres. Isso não está ainda totalmente desenhado, mas, seguramente, no próximo ano a gente vai poder se dedicar mais. ${ }^{1}$

SEA: Tirar o Eixo Nove do papel seria revolucionário porque realmente ele é muito forte. Alguma coisa que eu não perguntei 
que você queira registrar? Acompanhei, de longe, algumas das controvérsias que surgiram na imprensa em relação às críticas, ou mais bem ataques sofridos pela sua gestão nos últimos meses. Tenho ficado muito bem impressionada com a sua gestão toda e mais ainda com a delicadeza com a qual você tem manejado essas críticas. Deve ser muito complicado. LB: É complicado porque eu não sou delicada, então...

SEA: (riso) Não sendo delicada aí é fácil.

LB: Mas é uma loucura. A minha presença no ministério e o tipo de reação que ela provocou em alguns setores do movimento negro podem ter a ver com a percepção de que as mulheres negras estão tomando espaço demais.

SEA: Claro. Por cima uma feminista negra.

LB: Ah, gente, me deixa trabalhar! Mas é muito interessante isso tudo. É tanta coisa que as pessoas dizem a meu respeito, tantas coisas que dizem a respeito da gestão. Começou assim: "ela não sabe dialogar; ela não dialoga com o movimento social". Diga aí, alguém afirmar isso a meu respeito! É aquela velha técnica, as pessoas repetem, repetem, repetem mentiras...

SEA: Até que pareça verdade.

1 O Eixo Nove do Il Plano Nacional de Políticas para as Mulheres, de 2007, estabelece os seguintes objetivos, metas e prioridades:

Objetivo geral

I. Instituir políticas, programas e ações de enfrentamento do racismo, sexismo e lesbofobia e assegurar a incorporação da perspectiva de raça/etnia e orientação sexual nas políticas públicas direcionadas às mulheres.

Objetivos específicos

I. Ampliar o conhecimento sobre a dimensão ideológica do racismo, sexismo e lesbofobia;

II. Superar as dimensões de desigualdade baseadas no racismo, sexismo e lesbofobia;

III. Reduzir os índices de racismo institucional contra mulheres, garantindo o acesso equitativo às diferentes políticas públicas.

Metas

A - Formar 120 mil profissionais da educação básica nas temáticas de gênero, relações étnico-raciais e orientação sexual, em processos executados ou apoiados pelo governo federal;

B - Reduzir de $13,38 \%$ para $11 \%$ a taxa de analfabetismo das mulheres negras, entre 2006 e 2011 ; 
C - Ampliar em 5\%, entre 2008 e 2011 , a frequência de meninas, jovens e mulheres negras à educação básica;

D-Ampliar em 10\%, entre 2008 e 2011 , a frequência de mulheres negras no ensino superior;

E - Construir 950 salas de aula em comunidades remanescentes de quilombos;

F - Formar 5.400 professores/as da rede pública de ensino fundamental para atuar em comunidades remanescentes de quilombos;

G - Matricular 2 mil mulheres indígenas em cursos de Licenciatura Intercultural;

H - Qualificar $100 \%$ dos polos básicos para atenção integral à saúde da mulher indígena;

I - Implantar o Programa de Anemia Falciforme nas 27 Unidades da Federação;

$\mathrm{J}$ - Desenvolver experiências piloto para a implantação de diretrizes estratégicas de atendimento à saúde das mulheres lésbicas e bissexuais em cinco municípios do país;

$\mathrm{K}$ - Promover a articulação de cinco redes de monitoramento da mídia para denúncia de abordagens discriminatórias de gênero, raça/etnia e orientação sexual em todas as regiões do país;

L - Realizar três seleções públicas de projetos formulados por mulheres para produção de conteúdos de audiovisual que desconstruam os mitos e os estereótipos de gênero e raça/etnia; M - Capacitar 1 mil mulheres no âmbito do Plano Trabalho Doméstico Cidadão e articular para sua incorporação na Educação de Jovens e Adultos.

\section{Prioridades}

9.1. Formular e implementar programas, projetos e ações afirmativas e de enfrentamento ao racismo, sexismo e lesbofobia nas instituições públicas governamentais;

9.2. Fortalecer as políticas de enfrentamento da discriminação contra as mulheres atingidas pelo racismo, sexismo, lesbofobia, deficiência, fatores geracionais e outras formas de intolerância e discriminação;

9.3. Apoiar a capacitação de lideranças do movimento de mulheres e feministas na promoção de políticas e ações de enfrentamento ao racismo, sexismo e lesbofobia e ações afirmativas. 